\title{
RED CROSS APPEAL
}

Because of the situation in Cambodia and South Vietnam and in order to increase their assistance to the civilian populations of the two countries, the International Committee of the Red Cross and the League of Red Cross Societies launched an appeal to National Red Cross, Red Crescent, Red Lion and Sun Societies and to governments on 25 March 1975.

Current estimates put the number of displaced persons in South Vietnam at almost one million. The number of homeless in Cambodia is also put at around one million.

Although it is extremely difficult to carry out an exact assessment of needs, priorities are: foodstuffs, kitchen utensils, cloth and sleeping mats -all relief supplies which could be purchased locally. In addition, tents, medicaments, milk, tinned fish and meat must be sent into the countries.

The appeal was made for a three-month-long assistance programme. Costs are estimated at five million dollars, most of which is needed in cash. 